\title{
The First Report of Triple Advanced Synchronous Cancer: Bladder Transitional Cell Carcinoma and Clinically Silent Adenocarcinoma of Prostate and Colon
}

This article was published in the following Dove Press journal:

International Medical Case Reports Journal

\section{Mohammad Ali Ghaed (iD) Fatemeh Jahanshahi (iD ${ }^{2}$ Farid Maleki iD ${ }^{3}$ \\ 'Department of Urology, Rasoul Akram Hospital, Iran University of Medical Sciences, Tehran, Iran; ${ }^{2}$ Student Research Committee, Faculty of Medicine, Iran University of Medical Sciences, Tehran, Iran; ${ }^{3}$ Department of Surgery, Rasoul Akram Hospital, Iran University of Medical Sciences, Tehran, Iran}

\begin{abstract}
Multiple synchronous malignancies are believed to be quite rare and their diagnosis and treatment are very challenging for physicians. Co-presence of synchronous bladder and prostate cancers in an elderly individual is not uncommon; however, the simultaneous occurrence of the third cancer - colon cancer - is extremely outlandish. In the present study, the case of an 82year-old man with a complaint of hematuria is reported who was eventually diagnosed with three synchronous cancers: stage- 3 transitional cell carcinoma of the bladder, stage- 4 prostate mucinous adenocarcinoma, and stage-3 glandular adenocarcinoma of the colon. The patient underwent total colectomy and radical cystoprostatectomy followed by chemotherapy and radiotherapy. The 2-year follow-up showed promising results with no major complications and the patient's general condition was satisfactory. Although synchronous cancers are not so common, they should not be disregarded in elderly patients especially in those with multiple symptoms.
\end{abstract}

Keywords: adenocarcinoma, synchronous, cancer, carcinoma, prostate, colon

\section{Introduction}

Multiple primary malignant tumors were first described in 1889 by Billroth. ${ }^{1}$ Afterward, several cases of this kind were reported. Multiple primary cancers are categorized as synchronous, i.e. simultaneous occurrence or with a less-than-sixmonth-interval occurrence, and metachronous, implying a more-than-six-monthinterval occurrence. Generally, metachronous cancers are more prevalent than synchronous and are more observed in patients with a history of chemotherapy and radiotherapy. Contrary to double synchronous cancers, the occurrence of a triple is so uncommon with the prevalence rate of $0.5 \%$. $^{2,3}$

In the present study, the reported case is known to have a stage- 3 synchronous transitional cell carcinoma of the bladder together with two other clinically silent adenocarcinomas of the prostate at stage 4 and of the colon at stage 3 . To the best of our knowledge, this is the first report of the simultaneous presence of these three different advanced cancers in a patient in the English literature.

\section{Case Report}

An 82-year-old male patient with a complaint of dysuria and frequency, as well as gross hematuria and right flank pain, was admitted to the urology clinic. In the
Correspondence: Fatemeh Jahanshahi Rasoul Akram Hospital, Niayesh Ave. Tel +989124801231

Fax +98 21 64352353

Email Fjahanshahi.researcher@gmail.com 
history of the patient, other symptoms such as urinary retention, hesitancy, and dribbling were mentioned as well. But he did not state any symptoms of nausea, coffee ground vomiting, cramping and abdominal pain, diarrhea, constipation, melena, hematochezia, and incomplete bowel emptying. Also, he did not have any history of weight loss, smoking, chemotherapy, radiotherapy, and a positive family history of cancer.

In rectal examinations, the prostate was characterized as being abnormally large, which was justified due to the history of benign prostate hyperplasia yet uncontrolled by drugs.

Ultrasound study showed bladder wall thickening and right kidney with moderate hydroureteronephrosis.

The patient underwent cystoscopy during which, since a tumor was discovered at the anterior and right walls of the bladder, transurethral biopsy of bladder tumor was conducted and the sample was sent to pathology center to rule out bladder cancer.

In pathological observations, the involvement of lamina propria and thick muscle bundle of muscularis propria were seen, which were more compatible with a high-grade papillary urothelial carcinoma.

For further investigations and cancer staging, a spiral abdominopelvic computed tomography (CT) scan with and without contrast was requested. The $\mathrm{CT}$ image from the patient's bladder indicated a thick wall with soft tissue mass sized $22 \times 16 \mathrm{~mm}$ at the superoanterior part of the bladder (Figure 1). Furthermore, several retroperitoneal and para-aortic lymph nodes with the largest short axis diameter (SAD) equal to $8 \mathrm{~mm}$ were seen at the left paraaort. Additionally, moderate hydroureteronephrosis was observed in the right kidney (Figure 2). Surprisingly, a $40 \times 45 \mathrm{~mm}$ mass lesion in cecum together with lymph nodes with $6 \mathrm{~mm}$ SAD was found beside the tumor (Figure 3). Further investigations were conducted through colonoscopy and biopsy.

On colonoscopy, two pedunculated polyps were seen in the transverse and descending colon which were resected, and the specimens were missed because of poor colonic prep. And one polypoid mass with $3 \times 3 \mathrm{~cm}$ size in the cecum was seen in which specimen was noted adenocarcinoma.

At the multidisciplinary meeting, the survival rate of the patient and how successful the surgery would be were discussed, and the final decision was surgical intervention.

In this meeting, despite the lack of a report on the cytologic feature of the resected polyps, and because the gastroenterologist had described the lesions as grossly malignant

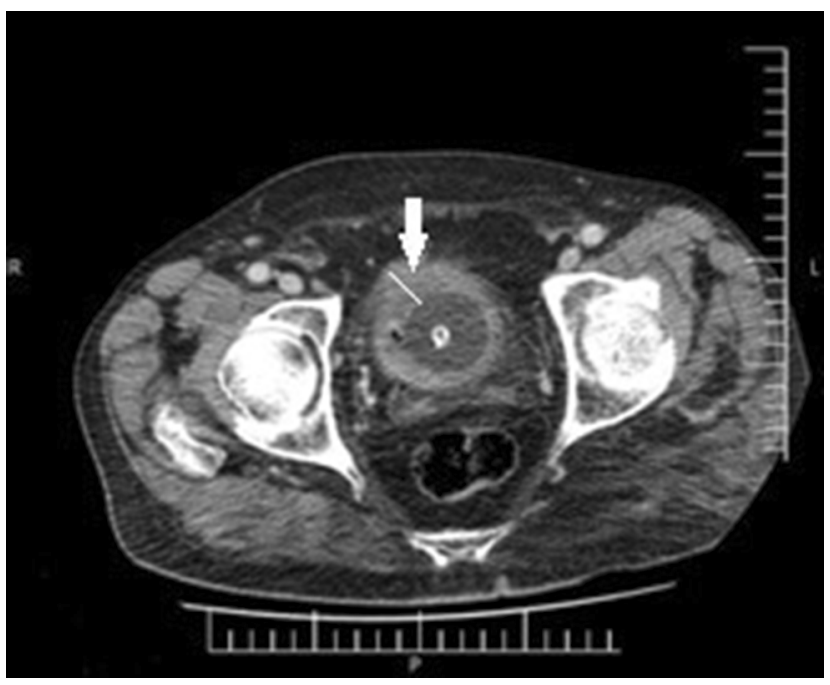

Figure I The CT scan axial cut revealed diffused bladder wall thickening (white arrow).

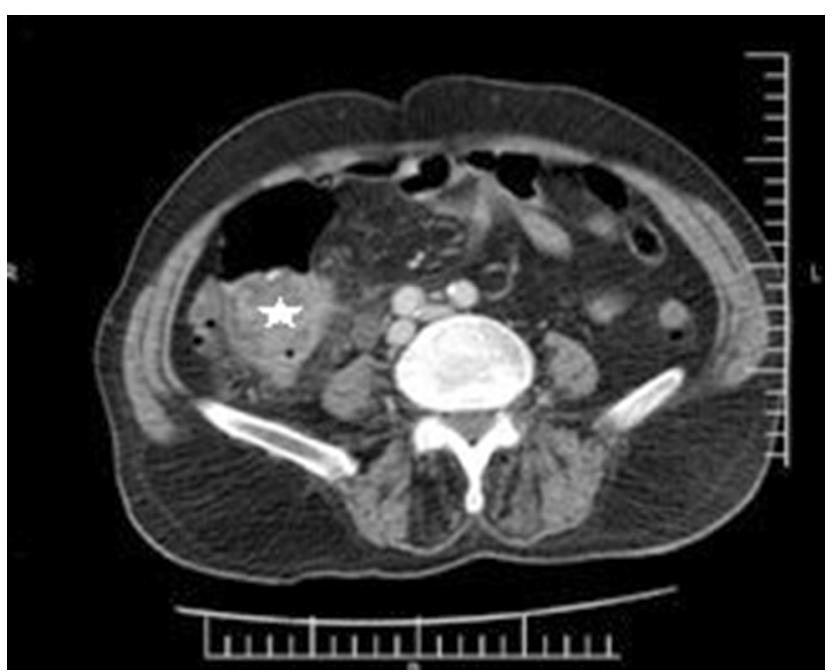

Figure 2 The abdominopelvic CT scan demonstrated the presence of $40 \times 45 \mathrm{~cm}$ soft tissue mass in the cecum (white star).

and the pathology of the other polyp had implied adenocarcinoma as well, the ultimate decision was made to conduct a total colectomy. Additionally, radical cystectomy was conducted due to the diagnosis of TCC of the bleeding bladder with no metastasis, which had made blood transfusion necessary and prostatectomy was inevitable as well.

Afterwards, the patient underwent general anesthesia and in Lloyd-Davies position, a midline incision was performed. The mass of cecum and lymph nodes were explored and total colectomy and lymphadenectomy and ileorectal anastomosis were conducted by a colorectal surgeon. Then, radical cystoprostatectomy and retroperitoneal lymphadenectomy were carried out and a bilateral urethrostomy was 


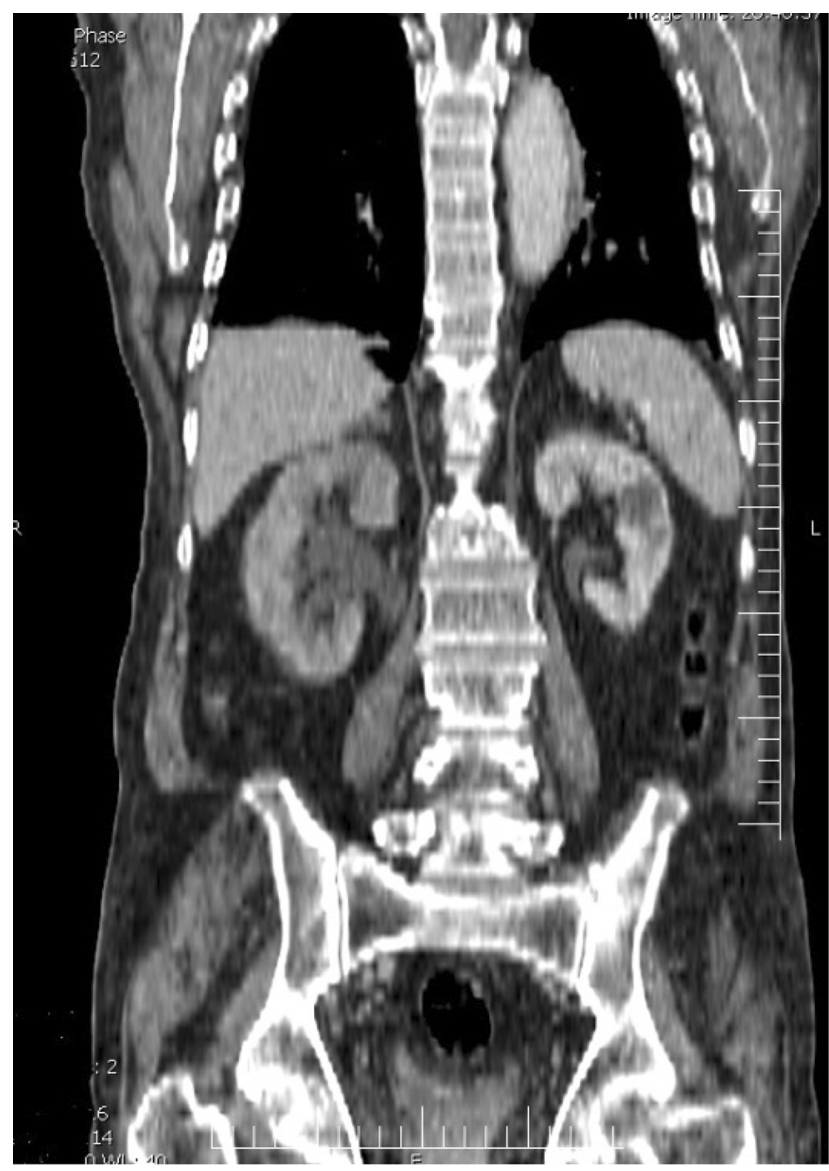

Figure 3 Hydroureteronephrosis in the right kidney in the coronal cut of abdominopelvic CT scan.

set by the urologist. The samples were sent to pathology separately.

Grossly, the total colectomy specimen included colon sized $90 \times 5.5 \mathrm{~cm}$, a portion of ileum sized $20 \times 1.8 \mathrm{~cm}$, cecum sized $6 \times 1 \mathrm{~cm}$, and omentum sized $40 \times 18 \mathrm{~cm}$. On opening, a gray polypoid mass sized $4 \times 3 \times 3.5 \mathrm{~cm}$ was identified near the ileocecal valve, with distances from proximal and distal margins 23 and $63 \mathrm{~cm}$, respectively. Apart from the whole specimen, there were 23 lymph nodes. The next one was a radical cystoprostatectomy specimen which included bladder sized $7.5 \times 7 \times 3.5 \mathrm{~cm}$, covered by perivesical fat sized $10 \times 5 \times 4 \mathrm{~cm}$, prostate gland sized $4.5 \times 3.5 \times 3 \mathrm{~cm}$, right seminal vesicle sized $3.5 \times 1 \mathrm{~cm}$, left seminal vesicle sized $2.5 \times 1.2 \mathrm{~cm}$, right and left vas deferens sized $7.5 \times 0.5 \mathrm{~cm}$ and $6.5 \times 0.4 \mathrm{~cm}$, respectively. The external surfaces of the specimen are unremarkable. On opening, a cream rubbery projected mass sized $1.8 \times 0.7 \times 0.5 \mathrm{~cm}$ is located on the anterior and lateral walls of the bladder. Cut section of the prostate gland revealed bilateral multifocal yellow discoloration up to $0.7 \mathrm{~cm}$ in diameter (Figure 4).

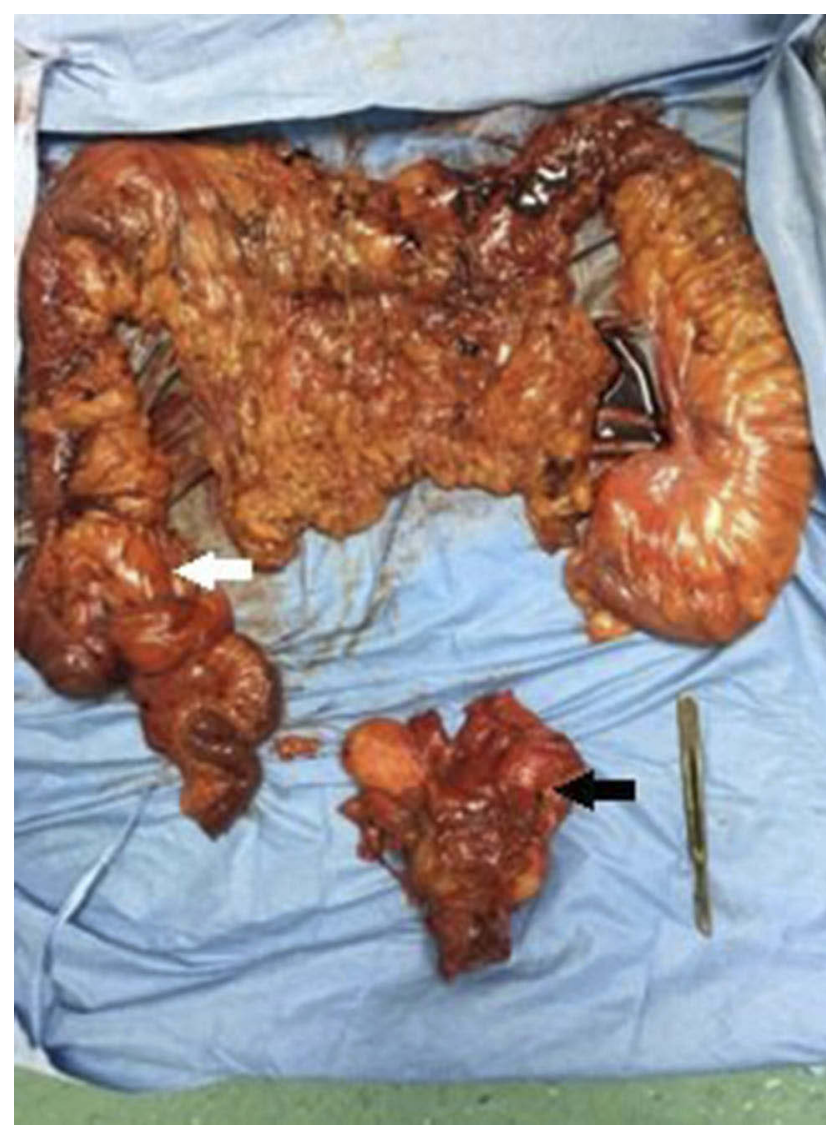

Figure 4 Surgical specimen following of total colectomy (the cecal mass was represented with white arrow) and total cystoprostatectomy (the specimen of prostate and bladder was highlighted with black arrow)

The right side of the pelvic lymph nodes consisted of three fragments of fibrofatty tissue sized $5 \times 4 \times 2 \mathrm{~cm}$ and six lymph nodes separated from the specimen.

The left side of the pelvic lymph nodes consists of three fragments of fibrofatty tissue measured $6 \times 4.5 \times 3 \mathrm{~cm}$, and eight lymph nodes separated from the specimen.

The right iliac lymph nodes consisted of one piece of fibrofatty tissue sized $5 \times 1.8 \times 1 \mathrm{~cm}$ and three lymph nodes separated from the specimen.

Histopathological reports demonstrated a total colectomy specimen with a tumor sized $4 \times 3.5 \times 3 \mathrm{~cm}$ in cecum which was invasive mucinous adenocarcinoma and had invaded the subserosal layer. All resected margins were free of the tumor. Additionally, no perineural and lymphovascular invasion was identified. Omentum also was free from tumor. All 23 dissected lymph nodes were free from the tumor, too. Two of the six right-sided pelvic lymph nodes were involved by metastatic adenocarcinoma, and one of the eight left-sided ones was involved by metastatic adenocarcinoma. Furthermore, all three right-sided iliac 
lymph nodes were involved by metastatic adenocarcinoma. The tumor-node-metastasis (TNM) classification of the tumor was $\mathrm{T}_{3} \mathrm{~N}_{0} \mathrm{M}_{0}$.

The pathology report of the bladder specimen with a tumor sized $1.8 \times 0.7 \times 0.5 \mathrm{~cm}$ demonstrated invasive transitional cell carcinoma with invasion to subserosa. Additionally, no perineural and lymphovascular invasion was found in the pathology report. The TNM classification of the bladder cancer was $\mathrm{T}_{3 \mathrm{a}} \mathrm{N}_{0} \mathrm{M}_{0}$.

Surprisingly, the prostate gland pathology reported bilateral adenocarcinoma with a histologic Gleason score of $7(3+4)$ and with the involvement of both right and left seminal vesicle. Moreover, both perineural and lymphovascular invasions were noted, though the extraprostatic extension was nil. Moreover, the TNM classification of the prostate tumor was reported $\mathrm{T}_{3 \mathrm{~b}} \mathrm{~N}_{2} \mathrm{M}_{0}$.

The recovery was uneventful, and after 20 days, the patient was discharged from the surgical service with a good general condition. Due to having triple synchronous high staged cancers, he was referred to oncologist for other necessary measures and underwent hormone replacement therapy with Diphereline (triptorelinembonate) 11.25 once every three months for the prostate cancer and 10 sessions chemotherapy treatment with 3-week intervals using Cisplatin $80 \mathrm{mg} / \mathrm{m}^{2}$ and Gemzar $1600 \mathrm{mg} / \mathrm{m}^{2}$ for the bladder cancer without requiring a chemotherapy regimen for colon cancer as a result of which showed a satisfactory response. In the 2-year follow-up, there was no sign of the tumor's recurrence.

Despite the poor expected survival rate, the patient's general condition was promising and he was proceeding with his treatment process.

\section{Discussion}

Multiple primary malignant tumors were first described in 1889 by Billroth. ${ }^{1}$ Later in 1932, Waren and Gate suggested diagnostic criteria consisting of 1) malignancy of any tumors should be confirmed through histopathology. 2) Minimum distance with intact tissue between two tumors should be $2 \mathrm{~cm}$ and if both are located on the same site, the minimum interval should be 5 years. 3) The possibility of metastasis should be ruled out. ${ }^{4}$ For years, these criteria were employed for distinguishing multiple primary malignant tumors; however, currently the two criteria of surveillance epidemiology and end result (SEER) and international association of cancer (IACR/IARC) are mostly applied.

Multiple primary malignant tumors are categorized as metachronous and synchronous that mainly differ in terms of intervals of malignancy occurrence. According to SEER if the interval between the occurrences of two malignancies is less than 2 months, it is considered as synchronous, otherwise, it is metachronous. However, IACR/IARC defines this interval threshold as 6 months. ${ }^{2,3}$

Based on a review on 1,104,269 patients with various cancers carried out by Irimie et al in 2010, multiple primary malignant tumors had a prevalence rate of $1.7 \%{ }^{5}$ Generally, synchronous cancers are less prevalent than metachronous cancers and it can be said that triple synchronous cancers have an approximate prevalence rate of $0.5 \%{ }^{3}$

According to the studies conducted by Jin et al and Weir et al, with more than 10 years of follow-up, statistics showed that from patients with prostate cancer $1.14 \%$ to $8.7 \%$ of whom received radiation therapy developed multiple primaries. ${ }^{6,7}$ By performing a systematic review on this topic, the risk of secondary malignancies in men with prostate cancer has been evaluated. Those patients who had received radiation therapy showed an increased risk of bladder cancer (HR 1.67) and colorectal cancer (HR 1.79). Moreover, it was assumed that there was a relationship between radiation therapy and the increased risk of urothelial and rectal cancers and sarcomas in the area affected by radiation, following at least a 5-year interval of no abnormality. Furthermore, progress has been made in distinguishing the genetic factors associated with secondary primaries in prostate cancer, most prominently BRCA2 mutations. However, until now, there has been no report of even a triple metachronous of these cancers and the present study is the first report of it. ${ }^{8,9}$

No distinguished etiology has been known for multiple primary malignant tumors till now. However, the effect of a history of radiotherapy and chemotherapy for metachronous cancers is suggested in the literature. While genetic defects and carcinogenic exposure are believed to have a role in synchronous cancers, ${ }^{10}$ either synchronously or metachronously, the simultaneous occurrence of the bladder and prostate cancers is not uncommon. ${ }^{11}$ Additionally, it can be claimed that, after urologic cancers, the most secondary prevalent non-urologic cancers are colon cancers. ${ }^{12}$ Nevertheless, until now, there was still no report of simultaneous occurrence of the cancers of the bladder, prostate, and colon, and the present case depicts an unprecedented pattern of the involvement of organs in advanced synchronous cancers.

We believe that the reporting and publishing of various patterns in organs' involvement is an effective tool for distinguishing synchronous cancers from metastatic ones and since synchronous cancers result in better prognosis 
and survival rate, this is an auspicious start for selecting the appropriate treatment approach.

Another notable feature of the present case would be that the stage 3 colon cancer in this patient was clinically silent and it was only diagnosed accidentally through the CT scan which was requested for staging the bladder cancer. Moreover, the prostate cancer, which was previously considered uncontrolled benign prostate hyperplasia and neglected, was diagnosed as a result of pathological investigations after the surgery. It can be, therefore, suggested that any suspicious masses found in investigations should be taken seriously even in patients with no clinical symptoms; , and aside from the metastasis scenario, the possibility of synchronous cancers should be investigated. As in this case, after the total colectomy and radical cystoprostatectomy in one session surgery, the patient could survive.

\section{Conclusion}

Since it is known that the probability of synchronous malignancies in elderly individuals is higher, the copresence of multiple tumors in them should be studied carefully.

Although synchronous cancers manifest in the elderly with multiple signs and symptoms, in the case of observing incidental lesions in imaging of the patients, necessary workup as well as careful investigations should be done to rule out the malignancy.

\section{Ethics Approval}

Institutional review board approval for case report is not required at our institution. Following the ethical principles, names of the patients were not pointed in the paper and the rights of the subject were protected. The patient received treatment consistently with the current standard of care.

\section{Consent for Publication}

Written informed consent was obtained from the patient for publication of this case report and any accompanying images.

\section{Acknowledgments}

The authors thank the Rasoul Akram Hospital Clinical Research Development Center (RCRDC) for its technical and editorial assists.

\section{Disclosure}

The authors report no conflicts of interest in this work.

\section{References}

1. Billroth T. [General surgical pathology and therapy. Guidance for students and physicians. Lecture]. Khirurgiia (Mosk). 1991; (10):136-143.

2. Koutsopoulos AV, Dambaki KI, Datseris G, Giannikaki E, Froudarakis M, Stathopoulos E. A novel combination of multiple primary carcinomas: urinary bladder transitional cell carcinoma, prostate adenocarcinoma and small cell lung carcinoma-report of a case and review of the literature. World J Surg Oncol. 2005;3:51. doi:10.1186/1477-7819-3-51

3. Peres YP, Almeida GL, Busato WFS Jr, Motta GO, Girardi F. Triple primary malignant tumors of bladder, prostate and lung: case report. J Clin Case Rep Rev. 2018;1:27.

4. Warren S, Gates O. Multiple primary malignant tumors. A survey of the literature and a statistical study. Am J Cancer. 1932;16:1358-1414.

5. Irimie A, Achimas-Cadariu P, Burz C, Puscas E. Multiple primary malignancies-epidemiological analysis at a single tertiary institution. J Gastrointest Liver Dis. 2010;19:69-73.

6. Jin T, Song T, Deng S, Wang K. Radiation-induced secondary malignancy in prostate cancer: a systematic review and metaanalysis. Urol Int. 2014;93(3):279-288. doi:10.1159/000356115

7. Weir HK, Johnson CJ, Thompson TD. The effect of multiple primary rules on population-based cancer survival. Cancer Causes Control. 2013;24(6):1231-1242. doi:10.1007/s10552-013-0203-3

8. Wallis CJ, Mahar AL, Choo R, et al. Second malignancies after radiotherapy for prostate cancer: systematic review and metaanalysis. BMJ. 2016;352:i851. doi:10.1136/bmj.i851

9. Vogt A, Schmid S, Heinimann K, et al. Multiple primary tumours: challenges and approaches, a review. ESMO Open. 2017;2:e00172. doi:10.1136/esmoopen-2017-000172

10. Song L, Li Q, Yang K, Yin R, Wang D. Three primary synchronous malignancies of the uterus, cervix, and fallopian tube: a case report. Medicine. 2018;97(24):e11107. doi:10.1097/MD.0000000000011107

11. Gheonea IA, Popp CG, Ivan ET, Gheonea DI. Unusual triple combination of prostate, lung and skin cancer. Rom J Morphol Embryol. 2017;58(2):567-574.

12. Zargar-Shoshtari MA, Saffari H, Moslemi MK. Metachronous occurrence of triple malignancies of kidneys, prostate, and breast. A case report and review of the literature. Case Rep Urol. 2013;2013:194620. doi:10.1155/2013/194620

International Medical Case Reports Journal

Dovepress

\section{Publish your work in this journal}

The International Medical Case Reports Journal is an international, peer-reviewed open-access journal publishing original case reports from all medical specialties. Previously unpublished medical posters are also accepted relating to any area of clinical or preclinical science. Submissions should not normally exceed 2,000 words or 4

published pages including figures, diagrams and references. The manuscript management system is completely online and includes a very quick and fair peer-review system, which is all easy to use. Visit http://www.dovepress.com/testimonials.php to read real quotes from published authors.

Submit your manuscript here: https://www.dovepress.com/international-medical-case-reports-journal-journal 